\title{
Analysis of Hydrodynamic Methods for Enhancing Oil Recovery
}

\author{
AL-Obaidi SH
}

\begin{abstract}
In the modern world, the hydrocarbons represent a raw material for various industries, therefore, the fight against the problem of extracting residual oil is relevant and important at this stage of human development. In connection with the high demand for hydrocarbons and the rise in world oil prices, research is being actively carried out on methods for enhancing oil recovery. Hydrodynamic methods of enhanced oil recovery represent one of the most effective and relevant methods by which the residual oil can be extracted. According to this, the current article pays special attention to several types of hydrodynamic methods for enhancing oil recovery. In this work it has been focused on three main types of hydrodynamic enhanced oil recovery methods; unsteady (cyclic) waterflooding, changing the directions of flows and forced fluid Extraction.
\end{abstract}

Keywords: Hydrodynamic methods, EOR, Cyclic, Unsteady, Residual oil, Fluid extracting.

*Author for Correspondence E-mail: drsudad@gmail.com

\section{INTRODUCTION}

The consumption of large quantities of petroleum products worldwide is increasing from year to year, but the efficiency of extracting fluid from oil reservoirs using industrial development methods is considered unsatisfactory in many countries.

The average oil recovery in the world is $25-$ $40 \%$. For example, in the countries of Latin America and Southeast Asia - 24-27\%, in Iran - $16-17 \%$, in the USA, Canada and Saudi Arabia - 33-37\%, in the CIS countries and Russia - up to $40 \%$. Residual oil reserves reach an average of $55-75 \%$ of its original reserves in the deposits [1][2].

Also, the number of fields with hard-torecover reserves has increased. Low oil recovery factors are due to the lack of necessary technologies for the development of hard-to-reach deposits.

Based on this, an urgent task in the modern world is the use of new technologies and methods for enhancing oil recovery in fields that are already in operation, where it is impossible to extract significant residual oil reserves using traditional methods.
Every year around the world, interest in enhanced oil recovery methods is growing, scientific, laboratory and field studies are being carried out to identify the most effective methods of stimulating the formation.

\section{GENERAL CHARACTERISTICS OF ENHANCED OIL RECOVERY METHODS}

For the application of enhanced oil recovery methods, it is fundamentally important to know the saturation of the reservoirs, how the residual oil is distributed in them and in what state it is in the pores. Incomplete displacement of oil by water from reservoirs is caused by micro- and macro-heterogeneity of reservoirs, wettability of the porous medium, interfacial tension, oil viscosity and recovery conditions.

Currently, dozens of different methods of influencing oil deposits and methods of increasing oil recovery are known, studied and introduced into industrial practice. They 
differ in the way they affect the productive formations, the nature of the interaction between the working agent injected into the formation and the fluid saturating the formation, and the type of energy introduced into the formation.

The effectiveness of the introduction of enhanced oil recovery methods largely depends on the level of knowledge of the properties of oil, gas and water saturating the formation, the state of its development and on the level of geological and field studies of the productive formation.

Studies of the formation include: studying the features of its structure, tectonic disturbances, areas of wedging of the productive zone of the formation with a detailed division of the horizon into separate layers and interlayers; studying the lithological characteristics of the rocks composing the formation; determining the structure of the porous space.

To use any method of increasing oil recovery, it is necessary to first study the geological characteristics of the composing rocks and saturating fluids, which, when implementing these methods, interact with the fluids injected into the formation, and this may be accompanied by adverse consequences for such an application.

For example, if clays are present in the reservoir, then the injection of fresh water, alkali or other substances into the rocks leads to swelling of clays and the loss of injection fluids. That subsequently makes the task of increasing oil recovery unrealizable. If highly mineralized brines are present in the reservoir, then when they interact with the injected fluids, solid crystals may precipitate with clogging of the reservoir pores.

Also for applying methods of increasing oil recovery, it is necessary to identify the nature of the occurrence of residual oil reserves in the reservoir after the initial exploitation of oil deposits [3][4].

Residual reserves in the formation can be in the form of a film of oil enveloping the rock grains, or in the form of oil accumulations between the rock grains, as well as in the form of lenticular inclusions not washed with water or individual interlayers not covered by waterflooding.

The state of the residual oil saturation is the determining factor for the correct choice of the enhanced oil recovery method. If the residual oil saturation is presented in lenses or interlayers not covered by waterflooding, then good results can be obtained using hydrodynamic methods of enhanced oil recovery. If the residual oil saturation is represented by film oil on the rock surface, then the preferred methods of enhanced oil recovery will be physical and chemical treatments [5][6]. The use of thermal methods is preferable if reservoir oils are highly viscous. Also of particular importance is a thorough, in-depth geological and field study of development targets, properties of reservoir oil, such as viscosity, density, and their variability within the reservoir.

To choose the most significantly increasing recoverable reserves and appropriate method of improving oil recovery, it necessary to have the following information about a particular field and the state on the market [7][8]: - oil, water and gas saturation of reservoirs or the degree of their depletion, flooding;

- reservoir oil and water viscosity, content of sulphur, paraffin, asphaltenes, resins, salts;

- reservoir properties of rocks composing the formation;

- location and technical condition of drilled wells;

- availability of material and technical means, their quality, characteristics and cost;

- oil selling price;

- the need to increase oil production.

Modern methods of increasing oil recovery are more or less based on waterflooding. Among them, four main groups can be distinguished [9][10][11]:

1) Hydrodynamic methods - cyclic flooding, changing the flow directions, forced liquid extraction;

2) Physical and chemical methods - waterflooding using active impurities (surfactants, polymers, alkalis, sulphuric acid, carbon dioxide, micellar solutions); 
3) Gas methods - water-gas cyclic action, oil displacement by high-pressure gas;

4) Thermal methods - oil displacement by heat carriers (hot water, steam), cyclic steam treatment, in-situ combustion, the use of water as a thermal solvent for oil.

Let's consider and analyze in more detail the main hydrodynamic methods of increasing oil recovery of fields.

A characteristic feature of these methods is the invariability of the placement system of injection and production wells, as well as the absence of the need to use additional energy sources introduced into the formation to extract residual oil. These methods function most often during waterflooding of oil reservoirs and are aimed at further intensification of natural oil recovery processes.

\section{UNSTEADY (CYCLIC) WATERFLOODING}

For the first time, the hypothesis about the effectiveness of unsteady waterflooding was formulated in the late 50s of the XX century [12]. This method was applied in many different oil fields, where it gave good results and subsequently quickly spread over the world. The essence of the cyclic impact method is that unsteady pressure is artificially created in layers that have heterogeneity in pore sizes, in the permeability of layers, interlayers, zones, and sections, and their uneven oil saturation caused by these types of heterogeneity [13].

It is achieved by periodically changing the reservoir operation mode by stopping and resuming water injection and extraction, due to which capillary and hydrodynamic forces are more fully used. This contributes to the penetration of water into areas of the formation that were previously unaffected [14].

Cyclic waterflooding is effectively used in fields where conventional waterflooding is used, especially in hydrophilic reservoirs, which capillary better retain intruded water in them, as well as for thick layered heterogeneous reservoirs and fractured-porous reservoirs.

In heterogeneous reservoirs, cyclic waterflooding is more efficient than conventional waterflooding. This is due to the fact that in the conditions of waterflooding of a heterogeneous formation, the residual oil saturation of the reservoir sections with the worst reservoir properties is significantly higher than the oil saturation of the main flooded part of the formation. When the pressure increases, the elastic forces of the formation and the liquid contribute to the introduction of water into the areas of the formation with the worst reservoir properties, while capillary forces retain the water embedded in the formation with a subsequent decrease in reservoir pressure.

As a result of the unsteady impact, timevarying impact on formations, waves of increasing and decreasing pressure periodically pass through these formations. Layers and sections of low permeability, saturated with oil, are located in formations haphazardly. These areas have low piezoconductivity, and the pressure propagation velocity in them is much lower than in highly permeable oil-saturated areas, so there are different pressure differences in sign between oil-saturated and flooded zones. With increasing pressure in the formation, i.e. with an increase in the volume of water injection or a decrease in fluid extraction, positive pressure drops occur - in the flooded zones the pressure is higher, and in the oil-saturated zones it is lower. When the pressure in the reservoir decreases, i.e. with a decrease in the volume of injection water or an increase in fluid extraction, negative pressure drops occur - in oil-saturated zones the pressure is higher, and in flooded zones it is lower.

Under the influence of alternating pressure drops, a redistribution of fluids occurs in an unevenly saturated reservoir, aimed at equalizing saturation and eliminating capillary imbalance at the contact between oil-saturated and flooded zones, layers and areas. The appearance of alternating pressures between layers of different saturation accelerates the capillary, counter-current water impregnation 
of oil-saturated zones (layers) - the penetration of water from flooded zones into oil-saturated zones along small pores and oil flow, from oilsaturated zones into flooded zones through large pore channels.Without alternating pressure drops between zones with different saturation, spontaneous capillary counter flow of fluids cannot occur due to the variable crosssection of pore channels, in which capillary displacement of oil by water is intermittent. The cyclical action on the reservoirs helps to overcome the intermittent nature of the manifestation of capillary forces, to equalize the saturation, i.e. increasing flooding coverage of heterogeneous formations. Changing the direction of fluid flows between wells enhances this process of increasing the sweep rate of waterflooding [15][16]. Since in the practical implementation of cyclic waterflooding, it is often not possible to simultaneously stop injection or production in all wells, the directions of flows should be changed. Cyclic (unsteady) waterflooding is one of the most effective hydrodynamic methods of increasing oil recovery and reducing the specific water consumption for oil production. The effectiveness of the method lies in the process of hydrodynamic water penetration into low-permeability elements of the reservoir due to uneven pressure redistribution caused by macro-inhomogeneity of the medium, and in capillary replacement of oil by water in lowpermeability zones of the formation.

This waterflooding method is used in many oil fields across the world. The important advantages of the method are the simplicity of its implementation, its applicability in a wide range of reservoir conditions, and a sufficiently high economic and technological efficiency.

\section{THE METHOD OF CHANGING THE DIRECTION OF FLOWS}

In the process of waterflooding of oil reservoirs, especially inhomogeneous ones, a pressure field and the nature of flows are gradually formed in them. However, individual sections of the reservoirs are not covered by the active process of oil displacement by water. As water appears in the production wells and the water cut increases, the flooded zones form isolated islands, the displacement of oil from which occurs only due to capillary impregnation of reservoirs with water. Since these processes are slow, the overall development efficiency decreases. The size and location of zones not covered by waterflooding depend not only on the heterogeneity of the reservoirs, but also on the arrangement of production and water injection wells, as well as on the general hydrodynamic situation in the reservoir, determined by the bottomhole pressure in the wells and the injection of fluid from them. Stable hydrodynamic conditions in the reservoir cause low mobility of oil in the stagnant zone [17].

To involve in the development of stagnant, not covered by flooding zones of the formation, it is necessary to change the overall hydrodynamic situation in it, which is achieved by redistributing water withdrawals and injection through wells [18]. As a result of a change in injection, the direction and magnitude of pressure gradients change, due to which the areas that were not previously covered by waterflooding are affected by higher pressure gradients, and oil is displaced from them into the flooded, flowing part of the reservoirs, thereby increasing oil recovery. But unlike cyclic waterflooding, the method of changing the direction of flows does not require the obligatory shutdown of production or injection wells. When implementing the method, along with a change in production and injection, periodic shutdown of individual wells or groups of production and injection wells is practiced [19][20]. Wells can be periodically stopped in one or in pairs. The method assumes a simultaneous limitation of production in some wells and an increase in others.

For the formation of cyclic waterflooding programs and the method of changing the directions of flows, the calendar of climatic conditions should be considered. It is not recommended to shut down production and water injection wells in winter in areas with sub-zero temperatures, since water may freeze in pipelines. 


\section{FORCED EXTRACTION OF FLUIDS}

Forced extraction of fluids is used at a later stage of development, when the water cut reaches more than $75 \%$.

At the same time, oil recovery increases due to an increase in pressure gradients and flow rates, which leads to the involvement in the development of reservoir sections and interlayers that are not covered by flooding, as well as the separation of film oil from the rock surface [21][22]. Thus, the technology of forced fluid extraction consists in a constant increase in the extraction of formation fluid, due to which a pressure drop is created between interlayers with different permeability.

As a result, oil from the oil-saturated (lowpermeability) interlayer is drawn into the hydrodynamic flow and carried out to the producing well.

The positive effect of forced fluid extraction on oil recovery can be associated with an increase in the oil displacement coefficient due to the action of the following factors [23][24]:

- In hydrophilic reservoirs, with an increase in the flow rate, capillary-trapped oil is involved in the development;

- In hydrophobic reservoirs, as a result of increased fluid extraction, a more effective additional washing of film-bound oil occurs.

Forced extraction is the most widely used method of enhanced oil recovery. It is currently used in many oil fields. In practice, the main approaches to the successful implementation of the method have been developed. It is necessary to start forced extraction gradually, increasing the flow rate of wells by $30-50 \%$, and then by $2-3$ times. The limit value of increasing the extraction is regulated by the capabilities of the method of well operation used.

For the application of forced extraction, highflow pumps and the use of a gas lift are required [25][26]. This technique can be very different: sucker rod pumps with a full load of equipment, electric pumps designed for large flows, etc.

\section{CONCLUSIONS}

Modern methods of enhanced oil recovery have got widespread industrial application and testing. According to the generalized data, the potential opportunities for enhancing oil recovery by various methods are as follows: thermal methods - $15-30 \%$, gas - 5-15\%, chemical - 25-35\%, physical $9-12 \%$, hydrodynamic $-7-15 \%$.

The advantage of hydrodynamic enhanced oil recovery methods is that they are relatively easy to implement and do not require large economic costs. The most mastered and frequently used of all hydrodynamic methods is the forced fluid extraction. But the production costs associated with oil and gas production are constantly growing, at the same time, oil prices are falling, which leads to the fact that the economic attractiveness of enhanced oil recovery methods decreases. At the same time, with the use of modern methods of increasing recoverable reserves from productive formations, the oil recovery factor is on average 30-70\% [27], of which $20-25 \%$ - by primary development methods (using the reservoir energy potential), and 25 $-35 \%$ - by secondary methods (waterflooding and gas injection to maintain reservoir energy) . Thus, the methods of enhanced oil recovery of oil increase the recoverable world oil reserves by 1.5 times, and this is up to 65 billion tons [28].

It was found the use of modern methods of enhanced oil recovery leads to a significant increase in the oil recovery factor. An increasing in oil recovery factor, for example, by only $1 \%$ in Russia as a whole, will make it possible to produce an additional 30 million tons per year.

Consequently, it can be argued that the demand for modern enhanced oil recovery methods is increasing, and their potential in increasing recoverable reserves is impressive.

\section{REFERENCES}

1.Yu.P. Zheltov (1986). "Development of oil fields". - M .: Nedra, 333. 
2. Al-Obaidi, Sudad H.(1996) . "Разработка Методики И Технологии Обработки Данных ГИС И Керна Для Определения Подсчетных Параметров Нефтегазовых Месторождений Ирака : На Прим. Месторождения Вост. Багдад." OSF Preprints, 10.31219/osf.io/f6vka .

3. Surguchev, M.L. and Gorbunov A.T. (1991). "Residual oil recovery methods". - M .: Nedra, 347.

4. Al-Obaidi, Sudad H. and Guliaeva NI. (2002). "Determination of Flow and Volumetric Properties of Core Samples Using Laboratory NMR Relaxometry." engrXiv,10.31224/osf.io/ t46wj .

5. Boyko, V.S.(1990). "Development and operation of oil fields". Textbook for universities, - M .: Nedra, 427.

6. Al-Obaidi, Sudad H.(1990) "Comparison of Different Logging Techniques for Porosity Determination to Evaluate Water Saturation." engrXiv, 10.31224/osf.io/fvj9u.

7. Surguchev, M.L. and Sharbatova I.N.(1988). "Cyclic impact on heterogeneous oil reservoirs". - M .: Nedra, 121.

8. Surguchev, M.L.(1985) . "Secondary and tertiary methods of enhanced oil recovery". M .: Nedra, 308 .

9. Al-Obaidi, Sudad Н. and Аль Обейди, Судад Х. (1996).“ Определение ГлиниСтости Продуктивных Пластов Месторождений Нефти И Газа Восточного Багдада." OSF Preprints, 10.31219/osf.io dmw9c .

10. Akulshin, A.I.(1988). "Forecasting the development of oil fields". - M .: Nedra, 240.

11. Al-Obaidi, Sudad H.(1998) . "Areas of Effective Application of Submersible Centrifugal Pump Installations with and Without a Gas Separator.” engrXiv, 10.31224 osf.io/2c $84 \mathrm{~h}$.
12. Akulshin, A.I.(1989). "Operation of oil and gas wells". - M .: Nedra, 480.

13. Al-Obaidi, Sudad H. 2004. "Modified Use of Microbial Technology as an Effective Enhanced Oil Recovery." OSF Preprints, doi:10.31219/osf.io/xgthz .

14. Cheremisin, N.A. and et al. (1997) . "Conditions for the formation of residual oil saturation in polymictic reservoirs during flooding".Oil industry, No. 9, 40-45.

15. Al-Obaidi, Sudad H.(1999) "Submersible Screw Pumps in Oil Industry."engrXiv, 10.31224/ osf.io/zqu3c .

16. Ovnatanov, S.T. and Karapetov , K.A. (1967). "Forced liquid extraction". - M .: Nedra, 131.

17. Gazizov, A.A. 2002. The increase in oil recovery from heterogeneous reservoirs atthe late stage of development. Moscow: Nedra-Businesscentre.

18. Al-Obaidi, Sudad H., Patkin AA, and Guliaeva NI. 2020. "Advance Use for the NMR Relaxometry to Investigate Reservoir Rocks." OSF Preprints,10.31219/osf.io/jmb9t.

19. Bailey, R.E. et al., 1984. Enhanced Oil Recovery, National Petroleum Council, Washington.

20. Al-Obaidi, Sudad H. (1996). "Разработка Методики И Технологии Обработки Данных ГИС." OSF Preprints, 10.31219/ osf.io/e68us .

21. Harwell, M.A. and Gentile, H.(2006). "Ecological Significance of Residual Exposures and Effects Oil Spill”. - M .: InTech, 246.

22. Hamida, T. and Babadagli, T. 2007. Analysis of capillary interaction and oil recoveryunder ultrasonic waves. Transp. 
Porous Med., no.70, 231-255.

23. Al-Obaidi, Sudad H. (1996) “Модификация Уравнения Арчи Для Определения Водонасыщенности Нефтяного Месторождения Восточный Багдад." OSF Preprints, 10.31219/ osf.io/ tqpn5 .

24. Harwell, M.A. and Gentile, H.(2006). "Ecological significance of residual exposures and effects oil spill". Moscow, InTech, 246.

25. Al-Obaidi, Sudad H., Galkin AP, and Patkin AA. (2006) . "Prospects of High Viscosity Oil Flow Rate in Horizontal Wells." OSF Preprints, 10.31219/osf.io/egq8s.

26. Altunina, L.K. and Kuvshinov, V.A. 2007. Enhanced oil recovery of viscous oildeposits using physical and chemical methods. Technologiya TEK, 1(32): 46-52.

27. Al-Obaidi, Sudad H., and Galkin AP. 2005. "Dependences of Reservoir Oil Properties on Surface Oil." OSF Preprints, doi:10.31219/ osf.io/789wp .

28. Muslimov, R.H. (2005). "Modern methods of enhanced oil recovery": The design,optimization and performance evaluation, Kazan, AN RT.

\section{Cite this Article}

Al-Obaidi SH. Analysis of Hydrodynamic Methods for Enhancing Oil Recovery. Journal of Petroleum Engineering and Technology. 2007; 6(3): 20-26p. 